\title{
DESIGNING FOR EQUITY, ACCESSIBILITY, DIVERSITY AND INCLUSION IN AN UNDERGRAD INDUSTRIAL DESIGN COURSE
}

\author{
Angelika SEESCHAAF VERES and Mariela GIULIANO \\ OCAD University, Toronto, Canada
}

\begin{abstract}
Centred on Inclusive Pedagogy, a third year undergraduate course in 'Design for Health', at OCAD University has approached the pandemic as a problem-based learning opportunity. Through the implementation of a layered approach that included Critical Design pedagogy, students were encouraged to acknowledge their own position in the design process, challenge biases in health care, and examine the technical layers that surround products, services, and systems. The course implemented outcomes, activities and assessments that supported students to become critical, responsible, and inclusive industrial designers. At the same time, similar inclusive principles and a Universal Design for Learning approach became the pedagogical basis for this online course, where curricular barriers were removed to provide accessible learning opportunities to all students. Combining ethnography and observational methods to guide the work, students were encouraged to engage in diverse design applications that drive innovation, decrease systemic barriers, and increase access to health and wellness.
\end{abstract}

Keywords: Industrial design, design for health, responsible design, universal design for learning, intersectionality, oppression, AEIOU, Micro-Meso-Macro, design interactions and experiences

\section{INTRODUCTION}

Recent social and economic stressors have emphasized the need for new ways of thinking, questioning, and problem-framing through interconnectivity, interdependence, adaptation, and resilience, while creating awareness of socio-technical and cultural structures, bias, and barriers. This paper describes a course that implemented critical design pedagogical methods to achieve adaptability and empathy, promote resilience, and include diverse learners through the application of Universal Design for Learning principles - resulting in a layered approach to accessible curriculum design. This course aimed to analyse and reframe the questions: How would a more equitable, diverse, and sustainable post COVID-19 world look like? How can we teach in a more accessible way that values, celebrates and embraces diversity in the class?

The "Design for Health" studio course, is offered during the third of a four-year BDes Industrial Design programme at OCAD University, the largest Art \& Design Institution in Canada. It is a studio format where students learn multiple theories, methods, and tools, and apply their knowledge and skills to the design of physical and digital products and services based on human factors and humancentred design. Offered during the pandemic, comprised of three sections with 25 students each, this course was facilitated fully online - a novel approach for studio learning in our institution.

The content was closely aligned with socially responsible design practice: "Design students work to provide a useful, enabling, and desirable product or service to those who are largely ignored by the market and /or other socio-cultural structures" [1]. Responsible design focuses its practices on those in need, who are overlooked, ignored, or otherwise underserved. This foundational knowledge is introduced, practiced and assessed while building up the formal, interactive, and aesthetic skills of undergraduate students in a university-level design education. 


\section{COURSE FRAMEWORKS}

The "Design for Health" studio course materials were constructed around the following four frameworks to build students' understanding and analysing of 'socio-technical determinants of health'.

\subsection{Social determinants of health model}

Students were introduced to the social determinants of health through readings, lectures and data visualizations. Health is more than medical care. Research shows that medical care, genetics and biology account for only $33 \%$ of variance in factors that contribute to our health [2]. The biggest contributors are individual behaviours, social circumstances, environment, all of which include multiple variables that, the authors would argue, can be positively influenced through critical design method and interaction designs that foster accessibility, inclusion, behavioural, social and systemic changes.

\subsection{Intersectionality and oppression}

The present course based its work on the 'Theory of Oppression' developed by black female lawyer and activist Kimberley Crenshaw in 1998, and intersectionality, which refers to the social, economic, and political ways in which identity-based systems of oppression and privilege overlap and influence one another [3].

\subsection{Micro-Meso-Macro framework}

This ethnographic analysis tool from the social sciences allows for observation and dissemination of how everyday experiences affect people differently, based on the intersection of their gender, ethnicity, and economic status. This framework also facilitates the analysis of the three layers that surround and impact individuals, including experiencing systems of privilege and/or oppression- on the individual (micro)- social (meso) and cultural \& institutional layers of our societies (macro) [4].

\subsection{Activities, environments, interactions, objects, and users (AEIOU)}

AEIOU [5] is an organizational framework that provides ethnographic analysis and synthesis methods for observational research. This framework prompts students /researchers to attend to, document, and code information under a guiding taxonomy to interpret results and apply to interaction design.

These four key frameworks were integrated into the teaching of product and industrial design methods, including human-centred design, human factors \& affordances, and interaction \& experience design. Frameworks and design theories were embedded in every aspect of the course including assignments, critique, in-class discussions and evaluation with the goal of increasing awareness and analysing the inherent biases and barriers that surround the way health care systems are constructed and experienced.

\section{COURSE ASSIGNMENTS}

The first assignments of the course built the basis of theories and methods that bridged into applied design approaches. Theories were integrated into activities that encouraged students to consider multiples perspectives during their design process. For the first half of the course, project assignments were completed in small groups to ensure students had the opportunity to practice their knowledge and skills with their peers in different contexts. This strategy was also part of an overall scaffolded approach to prepare students for the self-directed work completed at the end of the term.

One of the group assignments invited the class to describe and share selected experiences living in the pandemic. Students described several interactions such as getting a COVID-19 test, self-isolating in a family setting, grieving, or remote learning. This exercise aimed to centre the pandemic as the main context for the course, start to build community within the online studio classroom, and focus on individual lived experiences as the starting point of the learning process. Given the diversity of the classroom, students faced multiple identities, which in turn shaped their experiences with health care and the educational system. These reflections were further described and analysed using the AEIOU observational research framework, which helped students to identify different pain points, including systemic social-technical issues, and to frame opportunities for user-centred design interventions.

In addition, students individually plotted their intersectional identities into a Wheel of Oppression diagram [6]. A voluntary and anonymous class poll identified at least 10 dimensions on the chart where students self-identified as oppressed. These series of exercises meant to highlight the impact of sociotechnical factors on different contexts and scenarios. 
One more example is the bandage assignment. This group project asked students to analyse and visualize the interactions and touchpoints between two users during the process of applying a bandage to a cut wound. The users within the scenarios were purposefully selected with diverse gender and ethnic power imbalances to emphasize potential of different experiences. In this assignment, students were introduced to the Micro-Meso-Macro framework to map the interactions between people and assess their perceived barriers and pain points. Figure 1 shows how students integrated these three layers and combined them with the AEIOU framework to map out a user journey and visualize systems of oppression. Through this exercise, students further uncovered that a seemingly simple product such as a bandage is not neutral but holds systems of oppression in its design and materiality. Most bandages are matched to a white person's colour tone and visually represent how white supremacy looks when placed on the wound of a person of colour - acting as a double injury for the user: the accident itself (physical) as well as racism and oppression at large (emotional and mental factors). This critical and analytical approach shifted the design framework of problem solving to enquiring about the surrounding social, cultural and political mechanisms first [7].

Health Care Interaction Map Work Place Accident

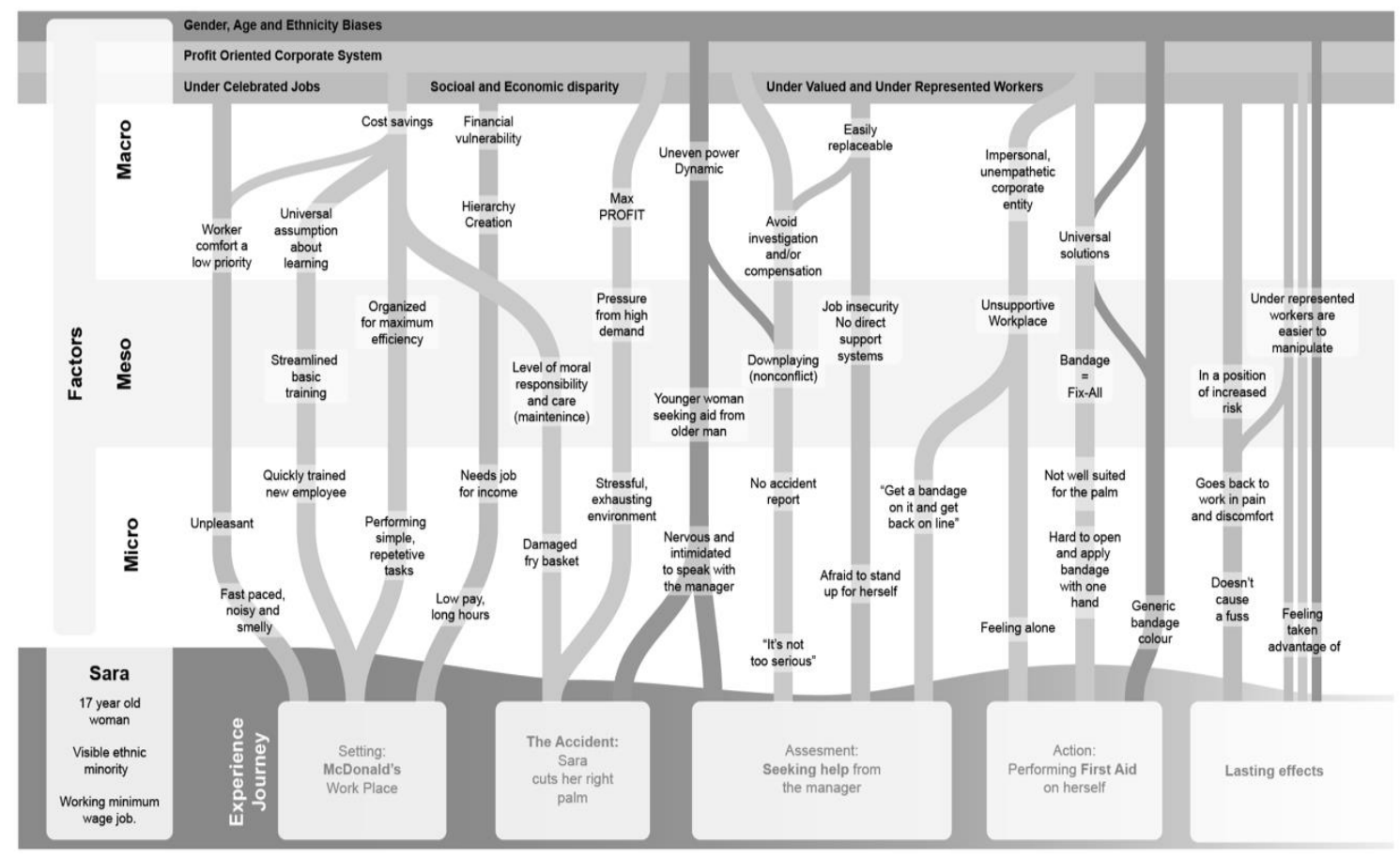

Figure 1. Student example of Bandage assignment. Interactions while integrating MicroMeso \& Macro layers

In the second half of the course, students embarked on a self-directed six-week project, themed around COVID-19, in which they applied all learned knowledge and skills to design a physical or digital product, service or system that found new opportunities to enhance health care for diverse communities during and after the pandemic. Although the work was independent, students were encouraged to continue consultations with their peers to bring different perspectives and considerations. Final projects were inclusive, accessible, and innovative with products to support intimacy at home, apps and connecting services to enhance access to mental health resources, systems to improve safety COVID19 measures in airports, or communication platforms for food sharing initiatives, to name a few.

At the end of the course, to optimize authenticity and engagement, the course instructor invited students to self-organize a public online showcase as part of an international design event "Design TO Festival", in January 2021. The opportunity to participate in this exhibition brought higher value and relevance to students' work as they had the chance to share their projects, learn from other designers and familiarize themselves with the international "design scene". Students proposed and discussed award winning products and app solutions that contribute, through design, to a more diverse and equitable approach to health, mental health and beyond - demonstrating that we can get there. 


\section{UNIVERSAL DESIGN FOR LEARNING (UDL)}

This studio course aimed to bring awareness of the impact of diversity and oppression into the design process through relevant theories and methods, but also with the implementation of an inclusive pedagogy that values diversity and creates a respectful and collaborative space. Since the initial design of the course, principles from UDL were incorporated into the syllabus. The UDL framework [8] acknowledges and values the vast differences in learners' interests as well as the way in which they perceive and process information, relate to the learning environment and show new knowledge. UDL supports all students to become purposeful and motivated, resourceful and knowledgeable, strategic and goal directed. UDL has three main principles that guide its application: multiple means of (a) engagement, (b) representation, and (c) action and expression. Table 1 lists how the UDL framework was applied.

Table 1. Examples of the application of UDL in the current course

\begin{tabular}{|c|c|c|}
\hline UDL Principles & Description & Applications in the course \\
\hline $\begin{array}{l}\text { Multiple means } \\
\text { of engagement }\end{array}$ & $\begin{array}{l}\text { Multiple means to engage } \\
\text { students and sustain their } \\
\text { motivation and interest in } \\
\text { the curriculum }\end{array}$ & $\begin{array}{l}\text { - Integration of lived experiences into the } \\
\text { learning process } \\
\text { - Choices on presentation dates and assignment } \\
\text { topics } \\
\text { - Visual maps to structure the course } \\
\text { - Opportunities to build community through } \\
\text { weekly group work and voluntary peer studio } \\
\text { spaces } \\
\text { - Participation in international design event } \\
\text { 'Design TO Festival' }\end{array}$ \\
\hline $\begin{array}{l}\text { Multiple means } \\
\text { of representation }\end{array}$ & $\begin{array}{l}\text { Multiple means to present } \\
\text { information that supports } \\
\text { and values diversity in the } \\
\text { classroom, such as } \\
\text { different language skills, } \\
\text { cultures, learning } \\
\text { preferences, abilities, or } \\
\text { previous knowledge }\end{array}$ & $\begin{array}{l}\text { Presentation of content in diverse ways (e.g., } \\
\text { videos, text, graphics) } \\
\text { - Diverse guest speakers bringing in multiple } \\
\text { perspectives of health/ medical/ anthropological } \\
\text { approaches } \\
\text { - Synchronous lectures recorded } \\
\text { - Connections with other disciplines } \\
\text { - Translation of theories, methods, and tools into } \\
\text { the product design context } \\
\text { - Guidelines to support respectful peer critiques, } \\
\text { and collaborative group work }\end{array}$ \\
\hline $\begin{array}{l}\text { Multiple means } \\
\text { of action and } \\
\text { expression }\end{array}$ & $\begin{array}{l}\text { Multiple opportunities for } \\
\text { students to navigate the } \\
\text { course and demonstrate } \\
\text { their knowledge }\end{array}$ & $\begin{array}{l}\text { - Student demonstration of knowledge in } \\
\text { multiple ways (e.g., choice of written } \\
\text { documents, mind maps, oral and visual } \\
\text { presentations, or videos to meet outcomes) } \\
\text { Video to share the course structure, clarify roles } \\
\text { and responsibilities, and provide suggestions to } \\
\text { navigate the course } \\
\text { Discussions about metacognition (to help } \\
\text { students know themselves as learners, acquire } \\
\text { new learning skills, and plan, monitor and } \\
\text { assess their own learning strategies) }\end{array}$ \\
\hline
\end{tabular}

\section{STUDENT FEEDBACK}

Student feedback was gathered through a survey that students completed at the end of the course, which included questions on students' self-perceived acquisition of critical thinking and creativity skills, identification of the most helpful assignment, the most effective learning strategies, and challenges 
within the course. This questionnaire encouraged students to reflect on their own learning journey, and it helped the instructor identify successes and challenges in the course. The questionnaire was completed by approximately $80 \%$ of the students. Since this activity was not designed as a research tool, it was not possible to complete a comprehensive qualitative data analysis in the current pilot. However, in the upcoming second iteration of the course, the authors are planning to incorporate qualitative and quantitative methods to critically assess the different components of the course.

When asked to identify the most helpful assignment, several students mentioned the Bandage project. Students described it as "impactful" as it helped them identify how social constructs and theories influence different scenarios. Students also appreciated many aspects of the final assignment (i.e., COVID-19 individual design project), in particular the appreciation of intersectionality, oppression, and accessibility during the prototyping phase. With regards to pedagogy, several students valued the inclusion of visualization tools to communicate information in more direct and accessible ways. Many students mentioned that they will be adopting these tools into their future practice. Finally, students explicitly highlighted how much they appreciated and learned through group work and peer studio spaces. They specifically mentioned how collaboration helped them navigate the course (especially in an online format), engage in critical analysis, learn from peers and stay accountable for the progress.

\section{LAYERED APPROACHES TO ACCESSIBLE COURSE DESIGN}

Figure 2 showcases our recommendations to create an accessible course that combines Critical Design, UDL and online teaching and learning best practices. The upper four layers in blue can be considered when designing an accessible learning environment for students, regardless of course content. The green layer at the bottom describes the course content, which can be adapted to multiple design courses. The red layer indicates access to physical facilities that were not possible during the pandemic but remain crucial for design studio practices.

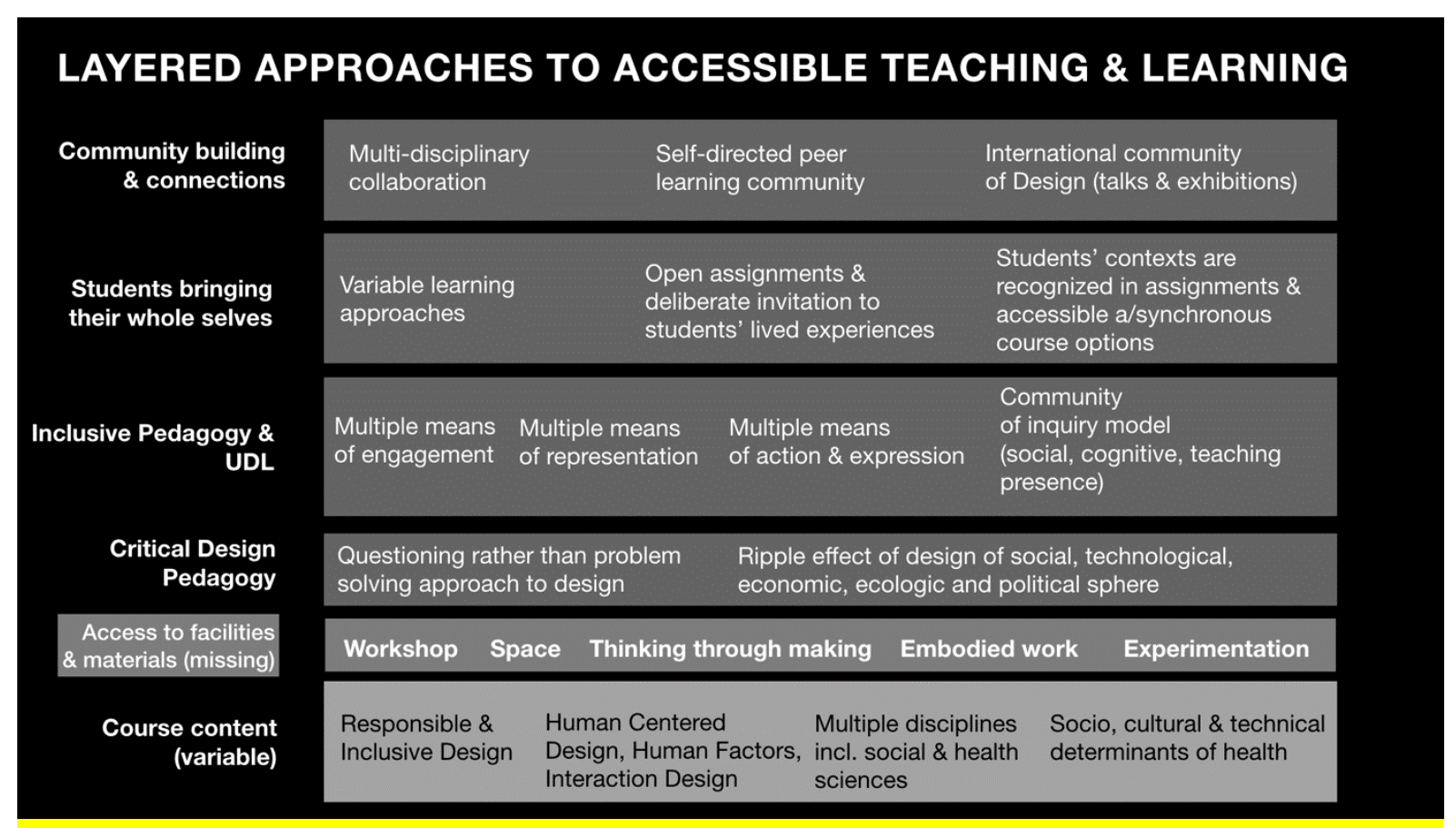

Figure 2. Diagram showing the layered approach to accessible teaching \& learning

\section{REFLECTION/CONCLUSION}

Situating this course content within the COVID-19 pandemic provided the context for the Design for Health course and allowed students to reflect on their own experiences. This approach helped students and faculty recognize the diversity of desirable interactions and outcomes through the understanding of socio-technical and cultural systems. This course applied critical design pedagogy to mentor responsible designers to become aware of systems of oppression when they design products, services and systems. Equally as important, the same principles were used to facilitate the course and provide accessibility and opportunities to all learners. We hope that these approaches helped students design a more equitable, 
diverse, and sustainable post COVID-19 world, in a classroom where they felt respected, valued and empowered to continue their long-life learning. We aspire to contribute to a broad design curriculum that develops students' critical skills to become self-directed learners and responsible designers while opening the practice to new mindsets.

\section{REFERENCES}

[1] Tharp B. M. and Tharp S. M Discursive Design, Critical, Speculative and Alternative Things, 2018, pp.43-55 (MIT Press).

[2] Goinvo, Social Determinants of Health-An open-source visualization of the social determinants of health. Available: https://github.com/goinvo/HealthDeterminants [Accessed on 2020, 10 August].

[3] Crenshaw K. Demarginalizing the Intersection of Race and Sex: A Black Feminist Critique of Antidiscrimination Doctrine, Feminist Theory and Antiracist Politics. Available: https://chicagounbound.uchicago.edu/cgi/viewcontent.cgi?referer=\&httpsredir=1\&arti cle $=1052 \&$ context=uclf, University of Chicago Legal Forum, Volume 1989, Issue 1, Article 8, pp. $139-167$.

[4] Social Science. Libre text. 1.4 B Levels of Analysis - Micro and Macro. Available: https://socialsci.libretexts.org/Bookshelves/Sociology/Book\%3A_Sociology_(Boundless)/01\%3 A_Sociology/1.04\%3A_The_Sociological_Approach/1.4B\%3A_Levels_of_Analysis_Micro_and_Macro [Accessed on 2020, 3 August], (2021) 20 February.

[5] Robinson R. Doblin (1991) Ethnohub, Documentation of online tools for qualitative research, AEIOU Framework. Available: https://help.ethnohub.com/guide/aeiouframework [Accessed on 2020, 21 July].

[6] Wong T. J. C. UC Calgary, Judge-me-not: By my circumstances. Wheel of Oppression diagram. Available: https://judge-me-not.weebly.com/fancy-terminology.html [Accessed on 2020, 18 July], (2013) 17 July.

[7] Ward M. Medium, Design Fiction as Pedagogic Practice, Towards a Fictionally Biased education. Available: https://medium.com/@ matthewward/design-fiction-as-pedagogic-practice9b1fbba7ae2b [Accessed on 2020, 25 October], (2013) 17 July

[8] Meyer A., Rose D., and Gordon D. (2014). Universal Design for Learning: Theory and Practice. Wakefield MA: CAST Professional Publishing. 